\title{
LA ENIGMÁTICA TRANSMISIÓN TEXTUAL DE AMADO Y ABORRECIDO 1
}

\section{Erick Coenen}

Departamento de Lengua Española, Teoría de la Literatura y Literatura Comparada, Universidad Complutense de Madrid (Facultad de Filología) Ciudad Universitaria. Edificio D, Despacho 304 28040 Madrid. España ewcoenen@pdi.ucm.es

[Anuario calderoniano (ISSN: 1888-8046), 4, 2011, pp. 33-54]

La comedia Amado y aborrecido de Calderón se publicó en la Octava Parte de Comedias nuevas escogidas, de 1657. Se volvió a imprimir dos décadas más tarde en la desautorizada Quinta parte de comedias de D. Pedro Calderón de 1677, en sus dos ediciones, la de "Barcelona» y la de Madrid. Un nuevo testimonio se incluyó en la Novena parte de comedias publicada póstumamente por Vera Tassis en 1691. En ausencia de manuscritos, y dando por muy improbable la existencia de una edición suelta que contenga un texto sorpresa, son estos los testimonios textuales a los que tendría que acudir principalmente hoy quien se propusiera editar la comedia.

${ }^{1}$ Este artículo profundiza en un problema que he tratado muy por encima en Coenen, 2011. Mis dos discusiones del problema pretenden ser complementarias. 
El enigma al que alude el título de estas páginas es el siguiente. Por un lado, el cotejo de textos da pruebas muy convincentes de una transmisión lineal del texto: el de 1677 deriva del testimonio de 1657, y el de 1691 deriva del testimonio de 1677. Por otro lado, ofrece pruebas no menos contundentes de que la edición de Vera Tassis, la de 1691, deriva de una rama de transmisión independiente. En lo que sigue, expondré las pruebas principales que conducen a estas conclusiones, y formularé dos hipótesis que permitirían reconciliarlas.

Veamos, primero, el eslabón inicial de la cadena: el que une el texto impreso en Comedias nuevas escogidas (en adelante CNE), de 1657, con el publicado veinte años más tarde en la Quinte parte (en adelante QP). En su mayor parte, éste deriva indiscutiblemente de aquél, ya que lo sigue a plana y renglón. No obstante, los compiladores de QP realizaron una serie de enmiendas sobre el texto que manejaron; una de ellas, que figura en un pasaje especialmente deturpado al final de la jornada segunda, de tal envergadura que tuvieron que abandonar el método a plana y renglón. Hay que añadir que la Quinta parte refleja la labor de un equipo poco escrupuloso y poco cuidadoso con los textos usados, por lo que cabe suponer que se trata de enmiendas improvisadas sobre la marcha, dejando sin tocar la gran mayoría de los pasajes corruptos.

El principal interés de las enmiendas de QP reside en que nos permiten vincular esta edición con la de Vera Tassis (VT) en la Novena parte de 1691. Veamos unos ejemplos.

En el folio 165 (por 166) de Escogidas, una dama llamada Irene pide socorro para que se intervenga en el duelo que están teniendo los caballeros Dante y Aurelio. Sus palabras son:

Llamad quien de tanto empeño el lance excuse. (fol. 166r)

Aparecen ligeramente modificadas en QP, y Vera Tassis reproduce la modificación con exactitud²:

${ }^{2}$ En las citas incluidas para el cotejo de variantes, no modernizo la ortografia ni la puntuación ni resuelvo las abreviaturas. Puede haber pequeñas diferencias entre las dos ediciones de QP; sigo aquí siempre la primera. 
Llamad quien de tâto empeño

el riesgo excuse.

(QP fol. 117v; VT p. 57; la cursiva es mía)

En el ejemplo siguiente, que es de un romance en é- $a$, faltan sílabas en el último verso y asonancias en los anteriores:

[LiDORO] en otra ocasión podràs

honrarme, que tan a vista

el seruicio pido el premio.

Malan Pues lo yerras (CNE, fol. 175r por 174r)

QP enmienda así:

[LiDORO] en otra ocasión podras

honrarme, que es accion necia,

si tâ a vista el servicio, pido el premio.

Malan Pues lo yerras (125v)

Esta enmienda parece haber sido el punto de partida de la deVT:

[LiDORO] en otra ocasión podras

honrarme, que es accion necia,

que a vista de tal seruicio

pido el premio.

Mal. Pues lo yerras

Si persisten dudas, creo que el siguiente ejemplo bastará para zanjar la cuestión. En CNE leemos:

Nis. Que intentas,

lleuando contigo a Irene?

Amin. Nise, assegurarme della, porque no falta quien diga que haze bateria de los zelos menos mal desde mas cerca. (fol. $175 \mathrm{v}$ por $174 \mathrm{v}$ )

Esta enmienda parece haber sido el punto de partida de la de VT: 
[LiDORO] en otra ocasión podras

honrarme, que es accion necia, que a vista de tal seruicio pido el premio.

Mal. Pues lo yerras

Si persisten dudas, creo que el siguiente ejemplo bastará para zanjar la cuestión. En CNE leemos:

NIs. Que intentas, lleuando contigo a Irene?

Amin. Nise, assegurarme della, porque no falta quien diga que haze bateria de los zelos menos mal desde mas cerca. (fol. $175 \mathrm{v}$ por $174 \mathrm{v}$ )

También aquí, falla la asonancia; pero en vez de insertar un verso en é-a después de "porque no falta quien diga", QP opta por acortar el pasaje:

Nis. Que intentas,

lleuando contigo a Irene?

Ам. Nise, assegurarme della, pues dizen que hazen los zelos menos mal desde mas cerca.

(fol. 126r; la cursiva es mía)

Salvo alguna minucia ortográfica, son idénticos los versos que ofrece aquí VT (p. 75), y no parece imaginable que QP y VT llegaran a la misma solución por caminos independientes.

A primera vista, estos ejemplos bastan para demostrar que VT depende de QP. Pero se pueden aducir otros que sugieren una historia textual bien distinta. Uno, procedente de la jornada primera, figura en la relación que hace Aurelio de su primer encuentro con Irene. El galán ha sufrido una caída de su caballo, motivo frecuente en Calderón. En la versión compartida por CNE y QP, Aurelio describe su situación así: 
Solo y a pie, como he dicho, sin norte, sin guía, y sin tiento, me hallé, cuando...

Son versos plenamente inteligibles que permiten la transición desde el tema de la caída a la descripción de la acción siguiente; pero VT inserta aquí nada menos que 22 versos más, que pongo en cursiva:

Solo y a pie, como he dicho, sin norte, sin guía, sin tiento, me hallé en la inculta maleza, las vagas huellas siguiendo de las fieras que, perdidas tal vez, tal cobradas, dieron conmigo en la verde margen de un cristalino arroyuelo que, del monte despeñado, descansaba en un pequeño remanso, $y$ para correr paraba a tomar esfuerzo. ¡Oh cómo sin elección del humano entendimiento sabe mostrarse el peligro, sabe sucederse el riesgo! Dígalo yo; pues llevado de mí sin mí, discurriendo al arbitrio del destino - que homicida de sí mesmo, sin saber dónde guía, sabe dónde está el peligro, haciendo de las señas del escollo seguridades del puerto-, me vi, cuando...

Digan lo que digan sus detractores, Vera Tassis no solía interpolar en los textos de Calderón tiradas largas de versos, y mucho menos sin motivo de peso. Se trata, además, de un pasaje muy susceptible de haberse perdido en ediciones anteriores por un salto del cajista, que pudo pasar involuntariamente del «me hallé» en el tercer verso citado al «me 
vi» en el último (que bien puede ser una enmienda de Vera, para evitar la repetición de «me hallé»).

En la jornada segunda, el pasaje más relevante para el estudio de la transmisión textual es el antes mencionado cuya extrema incoherencia obligó hasta a los despreocupados compiladores de la Quinta parte a interpolar unos versos. La situación dramática, tal como figura en la edición príncipe, es la siguiente. El protagonista masculino Dante y su criado Malandrín se hallan comentando, en versos manifiestamente corruptos, las actitudes contradictorias de Lidoro, que se acaba de marchar. De repente, interviene el Rey — que no se encontraba en escena-, dirigiendo una pregunta a Dante, de cuya respuesta se deduce que se ha producido un incendio y que Dante está sacando, o acaba de sacar, de las llamas a las dos protagonistas femeninas, Irene y Aminta. A la vez, se produce una transición de una silva pareada a versos de romance (á-a), pasando por unos renglones métricamente indefinibles. Es evidente que, al lado de otras corrupciones textuales, faltan en la princeps versos de transición entre la situación inicial y la del incendio:

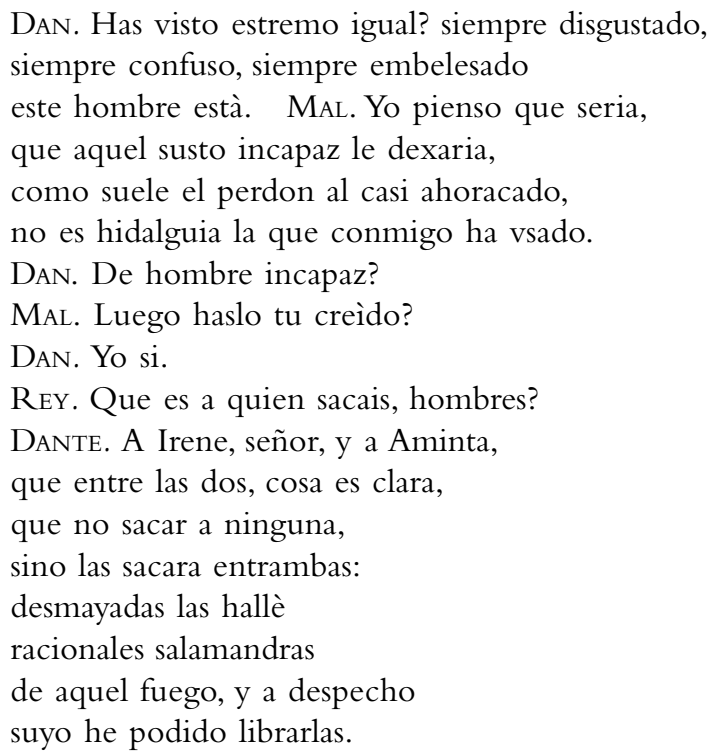

Ante tal incoherencia, los responsables de QP interpolaron aquí unos versos, al parecer de cosecha propia, para hacer más inteligible 
el texto, y llevaron a cabo alguna enmienda más. Muy hábiles no fueron; mantuvieron, por ejemplo, la interrogación después de «incapaz»; pero el resultado es indiscutiblemente más satisfactorio (la cursiva es mía, e indica variante textual frente a CNE):

DAN. Has visto estremo igual? siempre disgustado, siempre confuso, siempre embelesado este hombre està? MaL. Yo pienso que seria, que aquel susto incapaz le dexaria, como suele el perdon al casi ahoracado, DAN No es la hidalguia que conmigo ha vsado. de hombre incapaz?

MaL. Luego haslo tu creìdo?

DAN. Yo si.

MAL. Mas no oyes aquel ruido?

Fuego, fuego!

(Dent.)

MAL. La quinta

se abrasa toda

DANT. Irene, y Aminta

en ella: ay infeliz! mi mal que espera

MA. Al fuego se arrojò, locura fiera

Sale el Rey.

REY Quien vio desdicha mayor?

toda la quinta se abrasa,

Aminta està dentro della;

mas vn hombre entre las llamas

trae dos mugeres: valor

notable. MAL Señor, que sacas?

DANTE A Irene, señor, y Aminta,

que entre las dos, cosa es clara,

que no sacara a ninguna,

si no las sacara a entrambas.

Desmayadas las hallè, racionales salamandras

de aquel fuego, y a despecho

suyo he podido librarlas.

Muy distinto es el texto que ofrece Vera Tassis (la cursiva indica variante textual frente a $\mathrm{QP})$ : 
DÂ. Has visto extremo igual? Siempre assustado, siempre confuso, siempre embelesado este hombre está.

MAL.

Yo pienso que seria

que aquel susto incapaz le dexaria, como suele el perdón al casi ahorcado.

DÂ. No es la hidalguía que conmigo ha vsado de hombre incapaz.

MAL. Luego haslo tú creído?

DAnt. Yo sí. Mal. Yo no; $y$ si ha sido engañosa quimera, vamos trás él. D?t. En confusión tan fiera no sé lo que te diga, mucho á pensar, y discurrir me obliga.

MAL. Pues ¿qué has de hacer?

DANT. No sé. Deidades bellas, que el vso gobernáis de las Estrellas, qué queréis de una vida, que de tantos contrarios combatida, toda es delirios, toda es ilusiones, toda fantasmas, toda confusiones?

Suenan truenos, $y$ terremoto.

Mas Cielos, qué ruido es éste?

MAL. Qué ha de ser? pese a mi alma, que el Cielo se viene abaxo.

DANT. Gran terremoto!

MALAND. Ya escampa.

Dentro Vnos. Fuego, fuego.

VNos. Agua, agua. MaL. Vino para el susto.

DANT. Espera, aguarda;

que de tantos rayos vno en essa torre mas alta ha dado, y entre humo, y polvo, de su fabrica gallarda la travazon viene al suelo, con dos acciones tan varias, que al tiempo que cae con ruinas, en Volcanes se leuanta, 
siendo de vn instante á otro

piramide el que fue Alcazar.

IREN. dent. Qué me abraso!

Amin. dent. Qué me ahogo!

MAL. Si se ahogan, y se abrasan, mas que se abrasen, y ahoguen.

Suena la tempestad

DAN. Irene, y Aminta llaman

tan à vn tiempo que no dexan, ni aun aquella duda al alma

de elegir. Pero, qué tiene

que dudar por donde vaya

quien, con ir por donde pueda,

avra cumplido con ambas?

Vase, y sale el Rey, y Aurelio como deteniendole.

AUR. Lo primero es, gran señor, guardar tu vida. Rey. Si llama

Aminta, y está en el riesgo?

Aur. Yo basto solo á librarla;

no me estorves. Mas qué veo?

á pesar de tantas llamas,

vn hombre al cuarto de Aminta

entra despechado.

DANT. dent.

Caygan

sobre mí montes de fuego,

que todos ellos no bastan

a que no saque, á pesar

de la ruina, y de la llama,

en mis braços mi fortuna.

Sale Dante con Irene, y Aminta en brazos.

REY. Hombre, quién es á qui? sacas?

DAN. A Irene, señor, y Aminta;

que entre las dos, cosa es clara,

que no sacára á ninguna,

si no las sacára á entrambas.

Desmayadas las hallé,

racionales salamandras 
de aquel fuego, y á despecho suyo, he podido librarlas.

Como se puede observar, se han interpolado no menos de 50 versos que no figuran en ninguna de las ediciones impresas anteriores. Versos dignos de Calderón, además. Revisten una retórica muy calderoniana, y una fluidez que no es precisamente característica del mediocre poeta dramático que fue Vera Tassis, en los versos en los que el protagonista invoca a Diana y a Venus:

Deidades bellas, que el uso gobernáis de las estrellas, qué queréis de una vida, que, de tantos contrarios combatida, toda es delirios, toda es ilusiones, toda fantasmas, toda confusiones?

Se vislumbra asimismo la mano de Calderón en las metáforas volcánicas y piramidales, y en la búsqueda de la antítesis (cae / se levanta) que encontramos en estos versos:

entre humo y polvo, de su fabrica gallarda la trabazón viene al suelo, con dos acciones tan varias que, al tiempo que cae con ruinas, en Volcanes se levanta, siendo de un instante a otro pirámide el que fue Alcázar.

Pero acaso lo que más claramente señala a Calderón como autor de estos versos es la expresión del egoísmo cobarde de Malandrín. Se trata, por supuesto, de una característica bastante generalizada en los graciosos de comedia; pero en este caso, hay una gran semejanza con las palabras empleadas en una situación muy similar en otra comedia de Calderón. En una escena de Amar después de la muerte, don Álvaro Tuzaní se arroja a las llamas para sacar a su esposa Maleca del incendio de Galera. El gracioso Alcuzcuz, aun sabiendo que en la villa se encuentra también su amiga Zara, opta por no emular la hazaña del héroe y dice en su jerigonza morisca: 
como escaparme

yo, que Zara y la Galera

mas que se queme y se abrase. (vv. 2131-33) ${ }^{3}$

Encontramos el mismo uso de "mas que...» y un sentido similar en los citados versos de Malandrín en Amado y aborrecido:

Si se ahogan, y se abrasan,

mas que se abrasen, y ahoguen.

Estos indicios estilísticos de la autoría de Calderón; la extensión del fragmento interpolado, que con medio centenar de versos es extraordinariamente largo para una enmienda ope ingenii; y la índole no estrictamente necesaria de algunas de sus partes (amplificaciones retóricas, intervenciones humorísticas, etc.), hacen pensar que no estamos ante una compleja enmienda realizada por Juan de Vera Tassis, sino ante el texto tal como lo escribió Calderón, con, como mucho, alguna intervención menor de su editor póstumo.

A una conclusión similar llevan dos ejemplos de la jornada tercera. En uno, Vera completa dos redondillas cortas, a la vez que realiza unas cuantas mejoras más:

Quinta parte/Escogidas

REY. Què nueva lid de elementos confunden los orizontes, estremecidos los montes, y desatados los vientos? AUR. De vn instāte à otro se mueve tan violenta, que el mar sube, à dar, si es onda à ser nube, la que brama, ò la que mueve. Rey. Con mil palidos desmayos.

AUR. Dicha fue de la quinta.

REY. Y fuerça tambien serà, pues se desesperarà Aminta el passar la noche en ella.
Vera Tassis

REY. Què nueua lid de Elementos confunde los Orizontes, y estremeciendo los montes, và desatando los vientos? Aur. De vn instante à otro se mueue tan violenta, que el Mar sube à inquirir si es onda, ò nube la que brama, ò la que llueue. REY. Con mil palidos desmayos, de assombros los ayres llenos, nos estan diziendo a truenos, que presto vendràn los rayos. AUR. Dicha fue que de la Quinta estemos tan cerca ya.

REY. Y fuerça tambien serà, pues he de esperar à Aminta, el passar la noche en ella.

${ }^{3}$ Cito por la edición de Coenen, 2008. 
La imagen un tanto gongorina del mar subiendo "a inquirir si es onda o nube la que brama o la que llueve" posee las mejores cualidades de la poesía barroca y supera las limitadas capacidades poéticas de Vera Tassis ${ }^{4}$. Pero lo más llamativo son los tres versos que en las versiones anteriores faltan a la redondilla del Rey. Y es que la extraña idea de que los truenos anuncian los rayos, y no al revés de acuerdo con el orden natural, es peculiarmente calderoniana. Es fácil encontrar ejemplos de la misma inversión del orden natural en su obra ${ }^{5}$. También aquí, pues, habría que pensar que si estos versos son de Vera, consiguió hacer en ellos una imitación perfecta de los hábitos verbales y hasta de las costumbres mentales de Calderón; mucho más plausible resulta suponer que fue éste quien los escribió.

Una peculiaridad textual de la jornada tercera puede servir para completar las pruebas de que en ninguna de las tres jornadas VT puede derivar de QP. Se trata de un pasaje que sufrió sucesivos percances a lo largo de la transmisión del texto. Primero, fue víctima de un despiste del cajista al componer la página de CNE (Figura 1). Ésta tiene en su parte superior, a dos columnas, la parte final de un romance en $i$-a, debajo del cual empieza, en columna única, una silva pareada. El último verso de la columna izquierda ha sido colocado, por error, en el primer renglón de la silva; y a su vez, el primer verso de la silva se ha movido a la derecha, convirtiéndose en el último del romance. En consecuencia, las palabras con las que Aminta contesta a Dante («no os entiendo»), en vez de empezar con «No me admira, que tampoco yo me entiendo", empiezan con "que tampoco yo me entiendo", y aparecen no como palabras de Aminta sino como continuación de las de Dante. A la vez, el monólogo de éste ha sido puesto en boca de Aminta y empieza: «No me admira, a la gran prudencia / de los Dioses hacer en mi experiencia»; y entremedias se ha puesto en boca de Dante un verso que no guarda relación con su

${ }^{4}$ Fundo este juicio un tanto subjetivo en la lectura de las tres comedias de Vera que se incluyeron en la Parte 46 de Escogidas (Cuanto cabe en hora y media; El patrón de Salamanca y La corona en tres hermanos).

${ }^{5}$ Ver Coenen, 2008a. Sin embargo, añado, al entregar estas páginas a la imprenta, que desde que redacté este artículo en 2008, he podido comprobar que la misma inversión del orden natural de los rayos y los truenos aparece también en otros autores de la época. El hecho resta sin duda fuerza a mi argumentación, pero no creo que la invalide. 
contexto: «Sin duda, que convino». La composición de la página nos permite entender, aunque con dificultad, qué errores del cajista provocaron el caos resultante y nos deja restaurar el orden correcto de los versos. En QP, en cambio, la composición de la página es muy distinta, y al ser incorporados estos errores - no sin un rudo intento de enmendarlos-, los elementos textuales que deben unirse se han separado de tal modo que resulta ya imposible recolocarlos correctamente (Figura 2). No obstante, VT consigue recolocar los versos en su sitio original y dar su pleno sentido al fragmento, a la vez que enmienda el texto con perspicacia: hazaña que puede ser considerada imposible partiendo únicamente del texto de QP.

He aquí, pues, el enigma: por un lado,VT deriva demostrablemente de QP, y por otro, manifiestamente, VT no puede derivar de QP. Se me ocurren dos soluciones, no incompatibles entre sí en su parte más fundamental.

Una se funda en una suposición sobre el modus operandi en la imprenta de Francisco Sanz, donde se confeccionaron las nueve partes de comedias de Calderón editadas por Vera Tassis. No sería ilógico pensar que éste, en vez de transcribir las comedias de principio a fin y proporcionar los manuscritos resultantes al cajista, se limitara a entregar de cada comedia una lista de observaciones y enmiendas, para que el cajista las introdujera al componer el texto. Es decir, que el cajista trabajara sobre testimonios ya impresos — más manejables y más legibles que los manuscritos en aquel mundo carente de luz eléctrica-, manteniendo de ellos todas las corrupciones y otras peculiaridades que hubiesen escapado a la atención de Vera Tassis, a la vez que introducía los enmiendas de éste. En el caso de Amado y aborrecido, tal suposición explicaría la convivencia en un solo texto de variantes procedentes de QP — que sería el texto impreso manejado por el cajistay pasajes y enmiendas procedentes de otra fuente superior, fuese cual fuese. Ya Cruickshank y Bainton sospecharon que Vera había proporcionado a su impresor un ejemplar provisto de enmiendas marginales («a marked-up copy») de QP para el texto de Fieras afemina amor ${ }^{6}, \mathrm{y}$ si bien las enmiendas de Vera exceden a veces, en extensión o complejidad, lo que cabe en los márgenes de un texto impreso, la solu-

${ }^{6}$ En su estudio preliminar a Fieras afemina amor, p. 13. 
ción que propongo aquí parte de la misma idea: que Vera se ahorrara el trabajo de transcribir la friolera de 108 comedias, y que hiciera al cajista trabajar sobre esos mismos testimonios impresos, más o menos corruptos, que sus ediciones pretendían suplantar, pero provistos de enmiendas. Si esto fue el método de trabajo habitual, podría explicar también otras rasgos de las ediciones de Vera. No puedo entrar en ellos aquí, pero lo apunto en la convicción de que, ahora que hay varios proyectos en marcha que pretenden ofrecer por fin los textos más fiables posibles de las comedias de Calderón, urge establecer cómo trabajaban exactamente Vera y su impresor.

Si al menos en el caso de Amado y aborrecido es cierta esta suposición sobre la colaboración entre Vera y el cajista empleado por Francisco Sanz, cabe preguntarse de dónde procedía el texto alternativo de la comedia del que Vera sacó sus enmiendas. Conviene señalar aquí que, a diferencia de las ediciones anteriores, la edición de Vera Tassis de la comedia incluye en su encabezamiento la añadidura: «Fiesta que se representó a sus Majestades en el Salón Real de Palacio", de modo que parece razonable suponer que de tal «Fiesta» proceden sus enmiendas. Ya postuló Shergold que Vera, para otras comedias que publicó como "Fiesta que se representó a sus Majestades», pudo haber manejado textos provenientes de representaciones palaciegas en tiempos de Carlos II. Indicio de ello serían determinadas peculiaridades en las acotaciones, de las que también en Amado y aborrecido encontramos un ejemplo. Hacia el final de la comedia, los textos anteriores a VT indican que la nave en la que se encuentran algunos de los protagonistas «se va» (Vase el bajel, Escogidas, fol. 190r; QP, fol. 141v), lo cual sugiere que la obra fue representada originalmente sobre el agua, probablemente sobre el estanque del Buen Retiro (como anteriormente El mayor encanto, amor y sin duda unas cuantas comedias más). En la edición de Vera Tassis, la acotación aparece modificada leve pero significativamente: Ocúltase el bajel (p. 108). Lógicamente, al ser repuesta la obra en el salón del Palacio Real, el bajel no podía «irse» por el agua y se tuvo que acudir a otra solución.

Las representaciones palaciegas de comedias de Calderón eran casi continuas por aquellos años: en el Palacio de la Zarzuela, en el Buen Retiro, en el Salón Dorado, y muy a menudo en el Cuarto de la Reina Mariana. La categoría de «Fiesta» parece haber sido reservada para los espectáculos más elaborados, preparados con decorados impresionan- 
tes para ocasiones especiales, con la inclusión de entremeses, bailes y otros espectáculos menores. Hay muchas lagunas en la documentación conservada al respecto, pero está registrada una "fiesta» con el Faetón y Amado y aborrecido en enero de 1676, bajo la dirección de Antonio Escamilla ${ }^{7}$. Podríamos postular, manteniendo nuestra suposición sobre el modo de trabajo de Vera y el cajista, que aquél proporcionó a éste un ejemplar de la Quinta parte, acompañado de una lista de enmiendas procedentes del texto de dicha representación de 1676. Pero entonces tendríamos que preguntarnos de dónde procedía el texto de 1676.

La documentación conservada nos proporciona una pista importante al respecto. Entre los gastos declarados para la preparación de la «fiesta» de 1676 , figura un pago de 24,5 reales «al que tenía la segunda jornada de Amado y aborrecido, porque la diera ${ }^{8}$. Este ítem sugiere que Antonio Escamilla no tenía en su posesión un texto muy fiable de la comedia y que tuvo que trabajar con el texto de Escogidas, puesto que, como ya hemos visto, es precisamente en la jornada segunda donde éste presenta una laguna de tal magnitud y trascendencia que no puede ser remediada con una enmienda discreta. Cabe sospechar que Escamilla, al manejar el texto de Escogidas, se vio obligado a buscar en el mercado (¿negro? ${ }^{9}$ ) un manuscrito de la jornada más corrupta de las tres.

Parece seguro que la documentación es fiable en cuanto a que Escamilla, en efecto, sólo adquirió una de las tres jornadas, ya que el precio iguala exactamente una tercera parte del precio pagado por la otra comedia que se representó, el Faetón ${ }^{10}$. He aquí lo que a mi juicio es el punto más débil de la hipótesis que hemos ido construyendo en los párrafos anteriores. Ya hemos aportado evidencias contundentes de que Vera tuvo acceso a un texto alternativo y más autoritario

${ }^{7}$ I, 66-69. En los versos finales de Amado y aborrecido, se anuncia una representación de El pastor Fido; en efecto, se repuso esta comedia poco después (Shergold y Varey, 1982, pp. 71-75).

${ }^{8}$ Shergold y Varey, 1982, p. 67.

${ }^{9}$ En las declaraciones de gastos de las representaciones palaciegas, los acreedores figuran casi siempre con su nombre, por lo que no deja de ser sospechosa la omisión de los nombres de quienes proporcionaban manuscritos.

10 «Por el original de la comedia de Faetón, 73,5 reales que se dieron a quien la tenía» (Shergold y Varey, 1982, p. 67). 
no sólo de la segunda jornada, sino también de la primera y probablemente de la tercera, pero Escamilla, al parecer, sólo buscó tal texto alternativo de la segunda. De modo que el enigma no se resuelve suponiendo que Vera entregó al cajista un ejemplar de QP acompañado de una lista de enmiendas basadas en el manuscrito adquirido por Escamilla en 1676.

Podríamos añadir una suposición más a las anteriores, a saber, que el propio Calderón intervino en 1676 para enmendar las jornadas primera y tercera. Pero entonces, ¿por qué no lo hizo en la segunda, ahorrándole a Escamilla el trabajo de buscar su texto en otro lugar y el gasto de 24 reales y medio? Tal vez resulta más razonable suponer que, si bien Calderón, en efecto, pudo intervenir en la enmienda del texto impreso, no fue para la representación de 1676 sino para una "fiesta» posterior, de la que no se conservan referencias documentales. Tal suposición nos permitiría admitir también que Calderón realizó las enmiendas no sobre Escogidas de 1657 sino sobre la Quinta parte de 1677, lo cual a su vez haría innecesaria nuestras especulaciones sobre el método de trabajo de Vera y el cajista, ya que explicaría adecuadamente la presencia de variantes de QP en el texto publicado porVera.

He aquí, pues, la segunda de las dos hipótesis alternativas que anuncié. Puede ser resumida como sigue. En algún momento entre la primavera de 1677 (publicación de la Quinta parte) y la primavera de 1681 (muerte de Calderón), la comedia Amado y aborrecido fue representada en una fiesta palaciega, del que no se conserva documentación. Los comediantes aprovecharon para ello el texto publicado recientemente en la Quinta parte desautorizada. Calderón intervino en la enmienda del texto. El manuscrito resultante fue el que manejó Vera una larga década más tarde al preparar la Novena parte, no sin introducir alguna enmienda propia, como solía hacer. En consecuencia, el texto publicado por Vera reúne variantes de la Quinta parte, enmiendas ope ingenii suyas y enmiendas autorizadas por el propio Calderón.

¿Es plausible esta hipótesis? Dada la frecuencia con la que se representaban sus comedias, no parece probable que Calderón corrigiera siempre sus textos; pero sí que lo hiciera a menudo cuando se trataba de representaciones importantes, o sea, de representaciones palaciegas (recordemos que desde 1651, Calderón fue dramaturgo de la corte, y que empezó a escribir para los reyes ya en la década de los 
1630, o antes). Está documentada una de tales intervenciones ${ }^{11}$, y bien podemos suponer que fueron habituales. En cuanto al poco tiempo transcurrido entre la representación de Amado y aborrecido de 1676 y la hipotética reposición que postulamos aquí, tampoco tiene por qué sorprendernos, ya que tales repeticiones, incluso por compañías diferentes, no eran nada raras en palacio. Así, Las armas de la hermosura fue estrenada $^{12}$ en palacio en 1678 por Antonio de Escamilla y Matías de Castro, y repuesta apenas año y medio más tarde por Manuel Vallejo; y habiendo éste representado Afectos de odio y amor en el Buen Retiro el 11 de enero de 1680, ya el 4 de febrero siguiente representaba la misma comedia María Álvarez en el Palacio Real ${ }^{13}$.

Creo, por lo tanto, que esta segunda hipótesis es la que mejor resuelve el enigma de Amado y aborrecido, pero sería temerario dar esta solución por definitiva. Lo que parece claro es que el texto que publicó Vera Tassis deriva del que se usó para una representación palaciega de la comedia, fuese la que fuese, anterior a la muerte de Calderón. También parece claro que, cuando Vera Tassis alude a «Sus Majestades» en el encabezamiento no sólo de esta sino también de otras comedias, se refiere a quienes llevaban tal título cuando él imprimía sus tomos. Ahora bien, formalmente, Carlos II era Rey de España desde 1665, pero dada su minoría de edad, no pudo acceder al trono hasta 1675, y hasta su casamiento con María Luisa de Orleans el 11 de noviembre de 1679 no tenía consorte que justificara plenamente el uso del plural, «Sus Majestades». De modo que, si «Sus Majestades» significa "El Rey y la Reina», los encabezamientos de Vera sólo pueden referirse a representaciones posteriores a dicha fecha; y Calderón murió ya año y medio después (el 25 de mayo de 1681). Sin embargo, no creo que haya que tomar demasiado al pie de la letra el plural, al que podemos atribuir suficiente elasticidad para poder significar «La familia real» o "El Rey Carlos y la Reina Madre», en referencia a Carlos II y Mariana de Austria, que ejerció la regencia desde la muerte de Felipe IV.

11 «A don Pedro Calderón, 200 ducados por la loa y haber enmendado la comedia» (cursiva mía), ver Shergold y Varey, 1982, p. 88.

12 La representación de 1678 está documentada; al considerarla el estreno de la comedia, acepto la fecha propuesta por Hernández Araico, 1994, pp. 99-110, en contra de la defendida tradicionalmente (1652) por Hartzenbusch y Cotarelo.

13 Shergold y Varey, 1989, pp. 62-63 y 49-50. 
A falta de dramaturgos jóvenes de talla, Carlos II parece haber dado mucha importancia a la preservación de la ya muy consolidada posición de Calderón como dramaturgo de Corte. Sabemos que pidió al autor una lista de sus $\operatorname{comedias}^{14}$, y la documentación conservada sugiere que las representaciones de éstas se sucedieron a un ritmo vertiginoso en los primeros años de su reinado ${ }^{15}$. Conviene señalar también que el proyecto de imprimir póstumamente las comedias Calderón fue, asimismo, una empresa en cierta medida ligada al mundo palaciego. A fin de cuentas, la nobleza cortesana que asistía a las «Fiestas» constituía una categoría importante de los compradores potenciales de un libro de comedias; y si bien un libro de ese tipo se ponía a la venta pública, tenía siempre también un destinatario específico, a quien iba dedicado y que bien podía tener fresca en su memoria las representaciones aludidas. Así, Vera Tassis publicaba sus tomos bajo la protección de figuras tan principales como el Conde-Duque de Benavente, Gentilhombre de la Cámara del Rey, o el Duque de Frías, Condestable de Castilla y Camarero Mayor del Rey. A su vez, el impresor Francisco Sanz era nada menos que «impresor del Reino y portero de cámara de Su Majestad», según consta en los frontispicios de sus libros. El propio Vera Tassis acabó ejerciendo un oficio real como «fiscal de comedias» — calidad en la que firmó el último tomo de comedias de Calderón y en la que intervino en la censura de textos representados-, lo cual le liga tanto con la monarquía como con el mundo de los actores. En cuanto a éstos, los que actuaban en palacio eran básicamente siempre los mismos, y muchos de los más destacados eran de segunda generación - hijos de comediantes que habían actuado también en palacio-; es decir que eran personas plenamente integradas en el mundillo palaciego. En fin, la Corte era un pañuelo, y no se precisan grandes dotes de imaginación para entrever extensas redes de contactos aprovechadas por Vera Tassis para hacerse con los textos de comedias.

He abordado en otro lugar las implicaciones que puede tener el caso de Amado y aborrecido para la evaluación de la autoridad testimonial de otros textos publicados porVera. Baste aquí señalar que hay

${ }^{14}$ Es la lista conocida como la «de Marañón» y conservada a través de una copia manuscrita del siglo XVIII. Ver Wilson, 1962, pp. 95-102.

15 Shergold y Varey, 1975, pp. 176 y ss. 
decenas de comedias de Calderón ${ }^{16}$ que, sólo en su edición y en las derivadas de ella, llevan el encabezamiento de «Fiesta que se representó a sus Majestades» u otro similar. Lo mismo que Amado y aborrecido, sus textos derivan con toda probabilidad de representaciones palaciegas en tiempos de Carlos II, y pueden reunir corrupciones procedentes de la transmisión impresa con enmiendas del propio autor. La cuestión se vuelve especialmente aguda en casos como el de la segunda parte de La hija del aire, que en la versión de Vera Tassis incluye, entre otras particularidades, una conversación de 32 versos que no figura en la edición impresa de la que parece derivar su texto. Suele darse por sentado que esos versos son un apaño de Vera Tassis, pero bien pueden atestiguar una tardía intervención del propio Calderón en un un texto corrupto.

El enigma de Amado y aborrecido, insisto, sólo admite soluciones especulativas y por lo tanto provisionales y abiertas a discusión; bien puede ser que la realidad haya sido incluso más compleja de lo sugerido aquí. Lo que resulta casi incontrovertible es la convivencia, en un solo testimonio (VT), de claras huellas de un eslabón tardío de la transmisión impresa (QP) con variantes procedentes de un texto de autoridad muy superior, hoy perdido. Si los indicios de esto último no fuesen tan claros, habría sido fácil caer en el error de descartar el testimonio VT por carente de autoridad. Cabe la posibilidad de que haya otros casos similares pero menos llamativos, por lo que no podemos descartar del todo ni uno solo de los textos publicados porVera Tassis.

16 Coenen, 2011. 


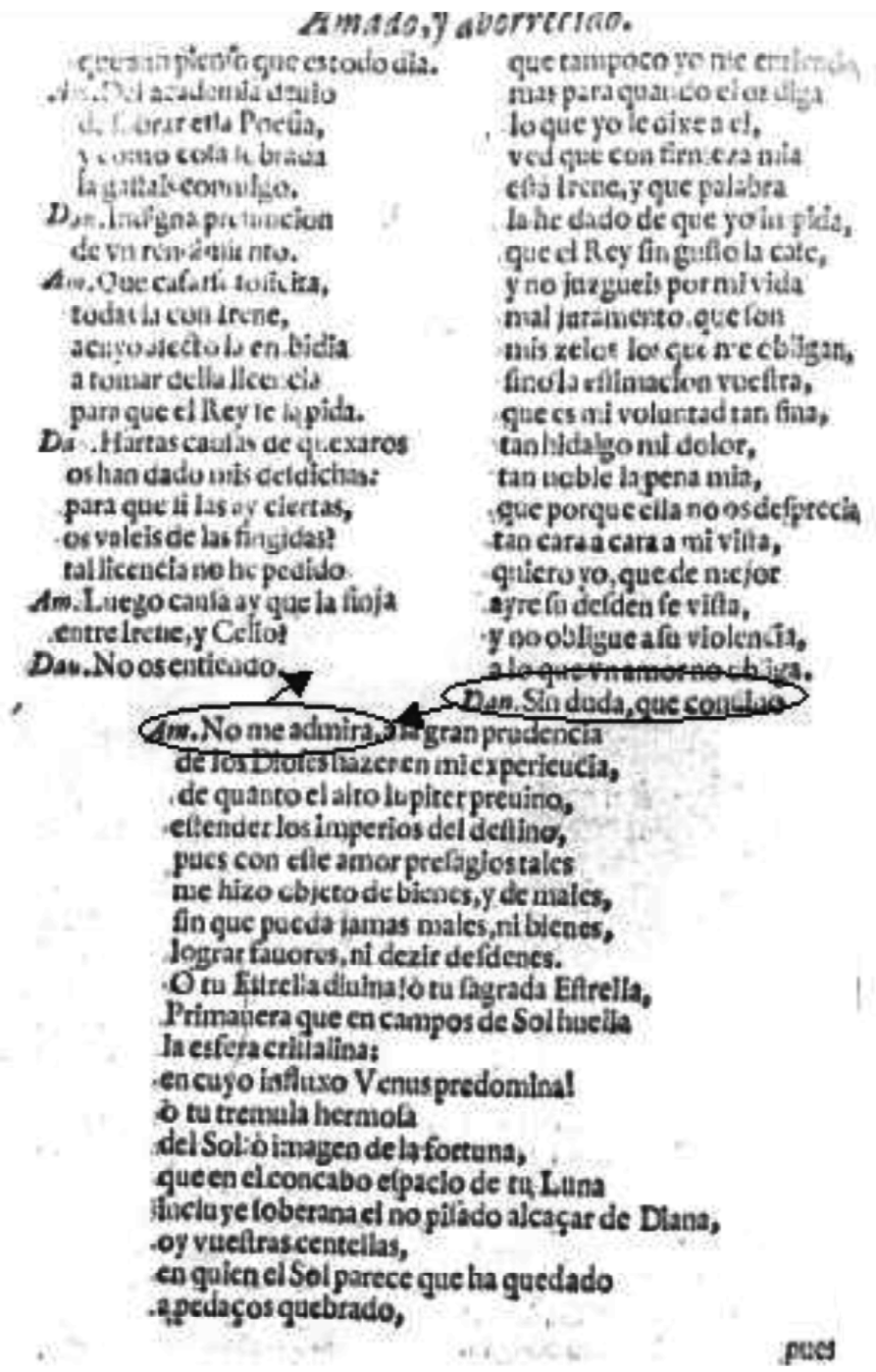

Figura 1.

Página de Escogidas (1657), con errores del cajista reconstruibles. 
De Dan Pediro Calderan.

eue aquette eftrangero es, fi aticodo a la bizartia de fuaccion primera.y luego a la de no amiftad confias, masde lo que dize efpro.

solk Dar. Què lo féa, o no, q̇ quita, ni què pone a mi dolor? fuele Irene, y quedó Aminta: fiambas fon mis Eltrellas, què me efpàta, y què me admira, que la feliz fea la errante, y la no feliz la fixa?

An Como a cfte jardin, guando ya la fombera pía lafaldala laz, entraiss?

Dant. Comola laz de tu villa defmiente tanto la noche, que iun pienfo gue es todo dia.

Amin Del acadeiniadejió de fobrar cffa Poeita, y como cola fobrada la gatas conmigo.

Dest Indias preliancion deva rendimiento.

Am Que calarfe folicina todavia con Irene, a cuyo 2 f cto ta la cabidia a tomar delia licencis para quecl Rey felayida.
Dant. Hartas caufas de quexasos os han dado mis defdichas: paraquè $\mathrm{I}$ las a ciertas osvaleis de las fingidas? tal licencia no he pedido. Am. Luego caufa ay que la finja entre Irene, y Celio:

peut. No os cnticndo. 3. Ni tampoco yo me entiendo, 4 inas paraquando èl os diga Joque yo le due a dl. ved que con firmeza mia elt Irene, y que palabra Ia be dido de que yo impida, quecl Rey fin gutio la cak, y no juzgucis, por mivida, nial juramento, que fen miszelos! os que m: obligan, fino la çftimacion vaeitss, que es mi volantad tan tma, tan hidalgo mi dolor, tan uoble lapena mia. que porque ella no os defprecia tah cara a cara a mi villa, quiero yo que de mejor ayre fiu derden fe vitta, yno oblizue a fu vioiencia a lo quern a mor noobliza.

Dant.Sin duda que conuko.

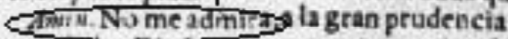
वetostolestiazer en mi experiencia, d: quanto el alto lupiter preuino, eftender los imperios del dettino, pues con efte amor prefagios rales me hizo objeto de birnes, y de males, fini que poeda jamasmales, nibienes, Ingrar fauores ni dezir defdenes. O tu Eitreila diuina! $o$ tu Agrada Eftrella, Primauera, que en canyos de Sol haclla la Exfera c:iltalina. ca cuyo iniluxo Venus ptedomina!

Figura 2.

Quinta parte («Barcelona», 1677): un rompecabezas ya apenas solucionable. 


\section{Bibliografía}

Calderón de la Barca, P., Amado y aborrecido, en Comedias nuevas escogidas de los mejores ingenios de España. Octava parte, Madrid, Andrés García de la Iglesia, 1657, fols. 165v-190v.

- Amado y aborrecido, en Quinta parte de comedias, Barcelona, Antonio la Cavallería, 1677, ed. facs. D. W. Cruickshank y J. E. Varey (Comedias XII), London, Tamesis, 1973, fols. 117r-142r.

- Amado y aborrecido, en Quinta parte de comedias, Madrid, Antonio Zafra, 1677, ed. facs. D. W. Cruickshank y J. E. Varey (Comedias XIII), London, Tamesis, 1973, fols. 117r-142r.

- Amado y aborrecido, en Novena parte de comedias... que nuevamente corregidas, publica don Juan de Vera Tassis y Villarroel, Madrid, Francisco Sanz, 1691, ed. facs. D. W. Cruickshank y J. E. Varey (Comedias XVIII), London, Tamesis, 1973, fols. 116r-142r.

- Amar después de la muerte, ed. E. Coenen, Madrid, Cátedra, 2008.

- Fieras afemina amor, ed. E. M.Wilson, estudio preliminar de D. W. Cruickshank y C. C. D. Bainton, Kassel, Reichenberger, 1984.

Coenen, E., «Rayos y truenos: sobre una metáfora predilecta de Calderón y su peculiar forma de aplicarla», Dicenda, 2008a, pp. 63-71.

- «Del libro al palacio, del palacio al libro. Una hipótesis sobre la transmisión textual de comedias de Calderón», Compostella Aurea, ed. A. Azaustre Galiana y S. Fernández Mosquera, Santiago de Compostela, Universidade de Santiago de Compostela, 2011, vol. III, pp. 75-83.

Cotarelo y Mori, E., Ensayo sobre la vida y obras de D. Pedro Calderón de la Barca, ed. facs. I. Arellano y J. M. Escudero, Madrid / Frankfurt, Iberoamericana / Vervuert, 2001.

Cruickshank, D. W. y Bainton, C. C. D., estudio preliminar a Fieras afemina amor, ed. E. M.Wilson, Kassel, Reichenberger, 1984.

Hernández Araico, S., «El mito de Veturia y Coriolano en Calderón: Las armas de la hermosura como Matrimonia reales», Criticón, 62, 1994, pp. 99110.

Shergold, N. D., "Calderón and Vera Tassis», Hispanic Review, 23, 1955, pp. 212-218.

Shergold, N. D. y Varey, J. E., Representaciones palaciegas: 1603-1699. Estudio y documentos, London, Tamesis, 1982.

- Teatros y comedias en Madrid: 1666-1687. Estudio y documentos (Fuentes para la historia del teatro en España, V), London, Tamesis, 1975.

- Comedias en Madrid: 1603-1709. Repertorio y estudio bibliográfico (Fuentes para la historia del teatro en España, IX), London, Tamesis, 1989.

WiLson, E. M., «An early list of Calderón's comedias», Modern Philology, LX, 1962, pp. 95-102. 